\title{
Extraction optimization of antioxidant polysaccharides from Auricularia auricula fruiting bodies
}

\author{
Yu ZOU ${ }^{1 *}$, Aili JIANG ${ }^{1}$, Mixia TIAN ${ }^{1}$
}

\begin{abstract}
The extraction conditions (liquid-solid ratio, temperature and time) of antioxidant polysaccharides from Auricularia auricula fruiting bodies (AAFB) were optimized using response surface methodology (RSM). The Box-Behnken experimental results showed the optimum extraction conditions as follows: a liquid-solid ratio of $38.77 \mathrm{~mL} / \mathrm{g}$, a temperature of $93.98^{\circ} \mathrm{C}$ and a time of $3.41 \mathrm{~h}$. Under these conditions, the maximal polysaccharide yield was $10.46 \mathrm{~g} / 100 \mathrm{~g}$. In addition, AAFB polysaccharides exhibited stronger antioxidant activities by evaluating of $\mathrm{Fe}^{2+}$-chelating ability and hydroxyl radical scavenging activity with $\mathrm{IC}_{50}$ values of 0.43 and $0.38 \mathrm{mg} / \mathrm{mL}$, respectively. These results indicated that AAFB polysaccharides might be potentially used as a natural antioxidant.
\end{abstract}

Keywords: Auricularia auricula; polysaccharide; extraction; antioxidant activity.

Practical Application: A. auricula polysaccharides can be potentially used as a natural antioxidant

\section{Introduction}

Active oxygen and free radicals are increasingly being recognized as being responsible for the pathogenesis of certain human diseases, including cancer, aging and chronic arterial disease (Moskovitz et al., 2002). In order to reduce the oxidative damage of active oxygen and free radicals, some synthetic antioxidants such as butylated hydroxytoluene (BHT), butylated hydroxyanisole (BHA) are widely used in food industry. Nowadays, natural antioxidants have become increasingly popular among consumers because synthetic antioxidants are often perceived as undesirable or harmful (Tu et al, 2009). Therefore, there is an increasing interest in studying natural antioxidants that can be used in food processing to improve body's antioxidant defenses and reduce the oxidative stress to human body.

The edible mushroom not only is a good source of nutrients, including protein, vitamin and dietary fiber, but also contains a variety of bioactive substances, such as polysaccharides, cordycepin and lectin (Xie et al., 2010). Previous publications indicate that some mushroom polysaccharides, isolated from Lentinus edodes, Agaricus nevoi, Coprinus comatus and Daedalea quercina, are found to have strong antioxidant activity (Asatiani et al., 2008; Chen et al., 2012). In addition, most of mushroom polysaccharides are relatively nontoxic and do not cause significant side effects (Wasser \& Weis, 1999; Zhang et al., 2007). Thus, mushroom polysaccharides have great development potential as a natural antioxidant.

Auricularia auricula (A. auricula) is a macro-fungus distributed in the Northeast Provinces of China. It has been used as food and drug in China for a long time. Fruiting bodies of A. auricula are rich in polysaccharides and are increasingly popular as a health food in China (Zou et al., 2013). Polysaccharide is considered to be one of the most important functional components in these health foods. However, most of this macro-fungus product is only used as cuisine materials, and many of its functional components are not fully developed and employed.

Response surface methodology (RSM) is an affective statistical technique for optimizing complex processes. It is wide used in optimizing the process variables. The extraction conditions of mushroom polysaccharides from Cordyceps militaris and Pleurotus eryngii have been optimized using RSM with Box-Behnken design (Chen et al., 2014; Zhang et al., 2014). It is considered that liquid-solid ratio, temperature and time are main parameters that can influence polysaccharide yield (Zhang et al., 2015).

The objective of this study was to develop an economical and efficient extraction of antioxidant polysaccharides from A. auricula fruit bodies (AAFB), and to investigate the effect of extraction parameters on polysaccharide yield. RSM was employed to optimize extraction conditions (liquid-solid ratio, temperature and time) in order to obtain the maximal polysaccharide yield. Meanwhile, antioxidant activity of AAFB polysaccharides was studied.

\section{Materials and methods}

\subsection{Materials}

Eighty grams dried fruiting bodies of A. auricula (grown in Dongning City and harvested in 2014) were purchased from a local market in Dongning City (Heilongjiang Province, China), pulverized and sifted through a $0.42 \mathrm{~mm}$ sieve. The powder 
(moisture content $12-15 \%$ on dry basis) stored in dark bags to prevent from moisture and light. BHT was purchased from Sigma Chemicals Co. (St. Louis, USA). All the other chemicals and reagents used in the experiment were of analytical grade.

\subsection{Extraction and purification of AAFB polysaccharides}

The extraction and purification of AAFB polysaccharides were carried out according to the method of Yan et al. (2014). In short, fruiting bodies powder of $A$. auricula was suspended in distilled water at the established volume and then stirred for extraction at the established temperature and time. The mixture was then centrifuged at $5000 \mathrm{rpm}$ for $20 \mathrm{~min}$. The supernatant was concentrated to $1 / 5$ of the original volume by evaporation (DZF-6020 vacuum oven, Shanghai, China) at $45^{\circ} \mathrm{C}$. Three volumes of absolute ethanol were added into the filtered solution and produced polysaccharide precipitate. The precipitated materials were collected by centrifugation at $5000 \mathrm{rpm}$ for $20 \mathrm{~min}$ and then purified using the classic Sevag method (Sevag et al., 1938).

\subsection{Experimental design}

The Box-Behnken experimental design with three factors and three levels was employed to optimize the extraction conditions in order to obtain the highest polysaccharide yield. Liquid-solid ratio $(A)$, temperature $(B)$ and time $(C)$ were chosen as independent variables in this design. Based on the singlefactor experiments (data not shown), $A(20,40$ and $60 \mathrm{~mL} / \mathrm{g}$ ), $B\left(60,80\right.$ and $\left.100^{\circ} \mathrm{C}\right)$ and $C(1,3$ and $5 \mathrm{~h})$ were determined as critical levels with significant effect on polysaccharide extraction. The complete design consisted of seventeen combinations including five replicates of the center point (Table 1).

The experimental results were analyzed by quadratic stepwise regression to fit the second-order Equation 1:

$Y=\beta_{0}+\sum_{i=1}^{3} B_{i} \mathrm{X}_{i}+\sum_{i=1}^{3} B_{i i} \mathrm{X}_{i}^{2}+\sum_{i=1}^{3} B_{i j} \mathrm{X}_{i} \mathrm{X}_{j}$ where $Y$ stands for polysaccharide yield, $X_{i}, X_{\mathrm{j}}$ for independent variables, $\beta_{0}$ for the model intercept and $B_{\mathrm{i}}, B_{\mathrm{ii}}$, $B_{\mathrm{ij}}$ for regression coefficients of variables for intercept, linear, quadratic and interaction terms, respectively. The software Design-Expert 7.0.0 Trial (State-Ease Inc., Minneapolis, USA) was used to obtain the coefficients of the quadratic polynomial model.

\subsection{Determination of polysaccharide content}

The determination of polysaccharide content was done by phenol-sulfuric acid method (Yan et al., 2014). Briefly, $1 \mathrm{~mL}$ of crude polysaccharide solution was mixed with $3 \mathrm{~mL}$ concentrated sulphuric acid to initiated the reaction, following $0.6 \mathrm{~mL}$ of $5 \%$ phenol was added and the mixture was kept at $100^{\circ} \mathrm{C}$ for $15 \mathrm{~min}$, after cooling to the room temperature, the absorbance of the reaction mixture was measured at $490 \mathrm{~nm}$ using a UV-2802 diode array spectrophotometer (UNIC, Princeton, USA). Polysaccharide content was calculated with d-glucose as standard.

\subsection{Assessment of antioxidant activity of AAFB polysaccharide}

Assay of $\mathrm{Fe}^{2+}$-chelating activity

The chelating activities of polysaccharides and BHT on $\mathrm{Fe}^{2+}$ were determined as reported by measuring the formation of ferrous iron-ferrozine complex (Dinis et al., 1994). Different concentrations of polysaccharides or $\operatorname{BHT}(0.2,0.4,0.6,0.8$ and $1.0 \mathrm{mg} / \mathrm{mL}$ ) were mixed with $3.7 \mathrm{~mL}$ of deionized water, and then reacted with $\mathrm{FeSO}_{4}(2 \mathrm{mM}, 0.1 \mathrm{~mL})$. The reaction was allowed to proceed for $30 \mathrm{~s}$. After $0.2 \mathrm{~mL}$ of $5 \mathrm{mM}$ ferrozine was added, the solution was mixed, left to stand for $10 \mathrm{~min}$ at room temperature, and then the mixture absorbance was determined at $562 \mathrm{~nm}$. The chelating activity of $\mathrm{Fe}^{2+}$ was calculated using the formula given below. $\mathrm{IC}_{50}$ (inhibitory concentration) was the concentration of the sample required to chelate $50 \%$ of $\mathrm{Fe}^{2+}$ (Equation 2).

Chelating ability $(\%)=\left(A_{0}-A_{1}\right) / A_{0} \times 100$

Table 1. Box-Behnken design and the response for polysaccharide yield extracted from A. auricula fruit bodies.

\begin{tabular}{|c|c|c|c|c|}
\hline Run & $\begin{array}{c}\text { A: Liquid-solid ratio } \\
(\mathrm{mL} / \mathrm{g})\end{array}$ & $\begin{array}{c}\text { B: Temperature } \\
\left({ }^{\circ} \mathrm{C}\right)\end{array}$ & $\begin{array}{l}\text { C: Time } \\
\text { (h) }\end{array}$ & $\begin{array}{c}\text { Polysaccharide yield } \\
(\mathrm{g} / 100 \mathrm{~g})\end{array}$ \\
\hline 1 & 40 & 80 & 3 & $10.07 \pm 0.31$ \\
\hline 2 & 20 & 100 & 3 & $7.39 \pm 0.30$ \\
\hline 3 & 20 & 60 & 3 & $5.86 \pm 0.19$ \\
\hline 4 & 40 & 100 & 1 & $6.41 \pm 0.26$ \\
\hline 5 & 60 & 100 & 3 & $6.46 \pm 0.25$ \\
\hline 6 & 40 & 80 & 3 & $10.13 \pm 0.51$ \\
\hline 7 & 20 & 80 & 5 & $4.96 \pm 0.13$ \\
\hline 8 & 60 & 80 & 5 & $4.85 \pm 0.17$ \\
\hline 9 & 20 & 80 & 1 & $4.59 \pm 0.18$ \\
\hline 10 & 60 & 60 & 3 & $6.21 \pm 0.30$ \\
\hline 11 & 40 & 80 & 3 & $10.30 \pm 0.49$ \\
\hline 12 & 60 & 80 & 1 & $5.11 \pm 0.17$ \\
\hline 13 & 40 & 80 & 3 & $10.29 \pm 0.46$ \\
\hline 14 & 40 & 60 & 1 & $4.59 \pm 0.16$ \\
\hline 15 & 40 & 100 & 5 & $9.63 \pm 0.38$ \\
\hline 16 & 40 & 80 & 3 & $7.74 \pm 0.23$ \\
\hline 17 & 40 & 60 & 5 & $4.13 \pm 0.16$ \\
\hline
\end{tabular}


where $A_{0}$ was the absorbance of the control (deionized water, instead of sample), and $A_{1}$ was the absorbance of the test sample mixed with reaction solution.

\section{Assay of hydroxyl radical scavenging activity}

The scavenging activity of AAFB polysaccharides on hydroxyl radical was determined by the method previously reported by Sun \& Kennedy (2010). Reaction mixtures in a final volume of $1.0 \mathrm{~mL}$ contained deoxyribose $(60 \mathrm{mM})$, phosphate buffer ( $\mathrm{pH} 7.4,20 \mathrm{mM})$, ferric trichloride $(100 \mu \mathrm{M})$, ethylene diamine tetraacetic acid $(100 \mu \mathrm{M}), \mathrm{H}_{2} \mathrm{O}_{2}(1 \mathrm{mM})$, and different concentrations of polysaccharides or BHT $(0.2,0.4,0.6,0.8$, and $1.0 \mathrm{mg} / \mathrm{mL}$ ). The reaction solution was incubated for $1 \mathrm{~h}$ at $37^{\circ} \mathrm{C}$, and then $1 \mathrm{~mL}$ of $1 \%$ thiobarbituric acid and $1 \mathrm{~mL}$ of $20 \%$ $(\mathrm{v} / \mathrm{v}) \mathrm{HCl}$ were added to the mixture. The mixture was boiled for $15 \mathrm{~min}$ and cooled on ice. The absorbance of the resulting mixture was measured at $532 \mathrm{~nm}$. The scavenging activity of hydroxyl radical was calculated according to the formula given below. $\mathrm{IC}_{50}$ (inhibitory concentration) was the concentration of the sample required to scavenge $50 \%$ of hydroxyl radicals (Equation 3).

Scavenging activity $(\%)=\left(A_{\mathrm{B}}-A_{\mathrm{S}}\right) / A_{\mathrm{B}} \times 100$

where $A_{\mathrm{B}}$ was the absorbance of the control (deionized water, instead of sample), and $A_{\mathrm{s}}$ was the absorbance of the test sample mixed with reaction solution.

\subsection{Statistical analysis}

The experimental results were expressed as means \pm standard deviation (SD) of triplicates. Statistical analysis was performed using Fisher's $F$-test and $p<0.05$ was regarded as significant.

\section{Results and discussion}

\subsection{Analysis of Box-Behnken experiment}

The extraction conditions including liquid-solid ratio, temperature and time as independent variables were optimized for the maximum polysaccharide yield. The Box-Behnken design and the corresponding response values are shown in Table 1.
A second-order polynomial model describing the correlation between polysaccharide yield and the three variables in this study was obtained in Equation 4 below:

$$
\begin{aligned}
& Y=-22.99+0.53 A+0.41 B+2.34 C-0.01 A^{2}-0.01 B^{2} \\
& -0.64 C^{2}-0.01 A B-0.01 A C+0.02 B C
\end{aligned}
$$

The statistical significance of Equation 4 was checked by $F$-test, and the results of analysis of variance (ANOVA) are shown in Table 2 . The model $P$-value of 0.0145 obtained by ANOVA indicated that the model was significant $(p<0.05)$. Meanwhile, the lack of fit $P$-value of 0.3836 indicated that the lack of fit was not significant $(p>0.05)$. For the model fitted, the coefficient of determination $\left(R^{2}\right)$ was 0.9135 implying that the sample variation of $91.35 \%$ for the polysaccharide yield was attributed to the independent variables. These results suggested that the developed model could adequately represent the real relationship among the parameters chosen.

\subsection{Effects of liquid-solid ratio, temperature and time on polysaccharides extraction}

As is shown in Table 2, temperature had significant linear effect $(p<0.05)$ on polysaccharides extraction; liquid-solid ratio and time had significant quadratic effect $(p<0.05)$ on polysaccharides extraction. However, none of the independent variables (liquid-solid ratio, temperature and time) interacted significantly $(p>0.05)$.

Figure 1 shows the effect of liquid-solid ratio and temperature on polysaccharides extraction from A. auricula fruit bodies at a constant time of $3 \mathrm{~h}$. At a fixed liquid-solid ratio, the polysaccharide yield increased rapidly when temperature reached a certain value (approximately $95^{\circ} \mathrm{C}$ ), and then leveled off. At a fixed temperature, the polysaccharide yield first increased and then decreased when the liquid-solid ratio was raised, but the variety of polysaccharide yield was slight when the temperature exceeded $85^{\circ} \mathrm{C}$. This indicated that extraction temperature was the principal effect on the polysaccharide yield. At a higher temperature, the solubility of polysaccharides in A. auricula

\begin{tabular}{|c|c|c|c|c|c|}
\hline Source & Sum of squares & Degree of freedom & Mean squares & $F$-value & $P$-value \\
\hline Model & 73.61 & 9 & 8.18 & 5.90 & 0.0145 \\
\hline A & 0.01 & 1 & 0.01 & 0.01 & 0.9607 \\
\hline B & 10.35 & 1 & 10.35 & 7.46 & 0.0293 \\
\hline $\mathrm{C}$ & 1.03 & 1 & 1.03 & 0.74 & 0.4174 \\
\hline$A^{2}$ & 21.68 & 1 & 21.68 & 15.63 & 0.0055 \\
\hline$B^{2}$ & 3.85 & 1 & 3.85 & 2.78 & 0.1394 \\
\hline$C^{2}$ & 27.58 & 1 & 27.58 & 19.89 & 0.0029 \\
\hline $\mathrm{AB}$ & 0.41 & 1 & 0.41 & 0.30 & 0.6037 \\
\hline $\mathrm{AC}$ & 0.09 & 1 & 0.09 & 0.07 & 0.7968 \\
\hline $\mathrm{BC}$ & 3.39 & 1 & 3.39 & 2.44 & 0.1622 \\
\hline Residual & 9.71 & 7 & 1.39 & & \\
\hline Lack of Fit & 4.84 & 3 & 1.61 & 1.32 & 0.3836 \\
\hline Pure Error & 4.87 & 4 & 1.22 & & \\
\hline Corrected Total & 83.32 & 16 & & $R^{2}=0.9135$ & \\
\hline
\end{tabular}

Table 2. Analysis of variance (ANOVA) of the response surface regression model. 
fruit bodies could be enhanced and the viscosity of the solvent decreased. Therefore, the whole extraction of polysaccharides was accelerated. However, increasing extraction temperature might result in more solvent volatilization, more energy cost and more impurities extraction (Lianfu \& Zelong, 2008). Therefore, the optimum extraction temperature should be about $95^{\circ} \mathrm{C}$ in the present study.

Figure 2 shows the effect of temperature and time on polysaccharide extraction from $A$. auricula fruit bodies at a constant liquid-solid ratio of $40 \mathrm{~mL} / \mathrm{g}$. When time was set, the polysaccharide yield increased rapidly when temperature was raised, which also implied that polysaccharide yield was significantly influenced by temperature. The polysaccharide yield increased when extraction time was extended from 1 to $3.5 \mathrm{~h}$ but slowly decreased when time continued to be extended. This phenomenon could be explained in terms of polysaccharides degradation. Biomacromolecule, such as polysaccharides, polyphenols and colorants, might degrade due to long time treatment under high temperature condition (Zou et al., 2010). Therefore, extraction time should not exceed $3.5 \mathrm{~h}$ in the present work.

Figure 3 shows the effect of liquid-solid ratio and time on polysaccharide extraction from $A$. auricula fruit bodies at a constant temperature of $80^{\circ} \mathrm{C}$. The increase of both liquid-solid ratio and time accelerated extraction of polysaccharides. However, above the optimal liquid-solid ratio (about $40 \mathrm{~mL} / \mathrm{g}$ ) and time (about $3.5 \mathrm{~h}$ ), the increase in liquid-solid ratio and time would not further increase the polysaccharide yield. This result was similar to those previously reported by Rodrigues et al. (2008). These findings make the whole process of polysaccharides extraction economically more feasible and efficient in the potential application in food industry.

\subsection{Optimization of extraction conditions and verification of model}

According to the RSM test results, the optimal extraction conditions to obtain the highest polysaccharide yield were determined as follows: a liquid-solid ratio of $38.77 \mathrm{~mL} / \mathrm{g}$, a temperature of $93.98^{\circ} \mathrm{C} \mathrm{min}$ and a time of $3.41 \mathrm{~h}$. The verification of the model was performed by the method previously reported by Derringer \& Suich (1980). Under the optimal extraction conditions, the polysaccharide yield was $10.46 \pm 0.34 \mathrm{~g} / 100 \mathrm{~g}$, and this value was not significantly different $(p>0.05)$ from the predicted value of $10.41 \mathrm{mg} / 100 \mathrm{~g}$. These data proved that the model designed in this study was valid.

\section{4 $\mathrm{Fe}^{2+}$-chelating activity of $A A F B$ polysaccharides}

The previous research reported some transition metals, such as $\mathrm{Fe}^{2+}, \mathrm{Cu}^{+}$and $\mathrm{Co}^{2+}$, could trigger process of free radical reaction to magnify the cellular damage (Gungor \& Sengul, 2008). Among these metal ions, $\mathrm{Fe}^{2+}$ was known as the most powerful pro-oxidant due to its high reactivity, which accelerated lipid oxidation by breaking down hydrogen and lipid peroxidase to reactive free radicals via the Fenton reaction (Sun \& Kennedy, 2010). In this study, ferrozine could react with $\mathrm{Fe}^{2+}$ to form red complexes of ferrozine- $\mathrm{Fe}^{2+}$. When there was other chelating agent, the ferrozine- $\mathrm{Fe}^{2+}$ formation was disrupted which

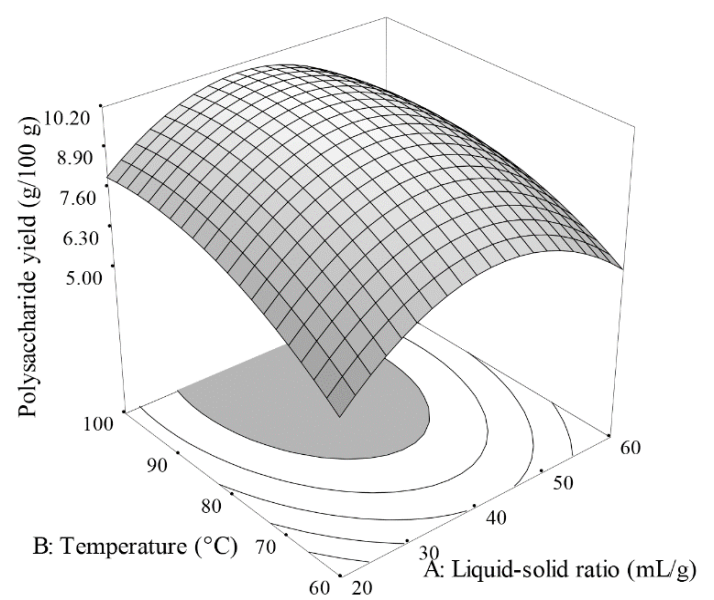

Figure 1. Response surface plot showing the effect of liquid-solid ratio and temperature on polysaccharides extraction from $A$. auricula fruit bodies. The time was constant at $3 \mathrm{~h}$.

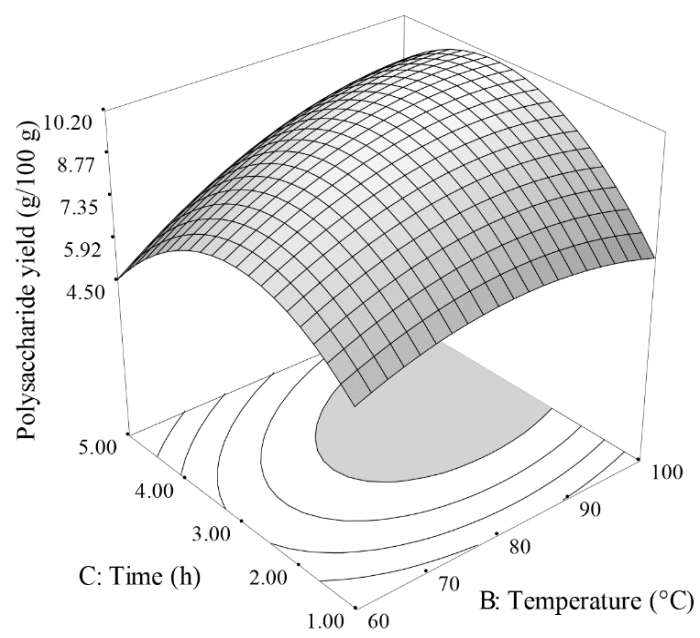

Figure 2. Response surface plot showing the effect of temperature and time on polysaccharides extraction from A. auricula fruit bodies. The liquid-solid ratio was constant at $40 \mathrm{~mL} / \mathrm{g}$.

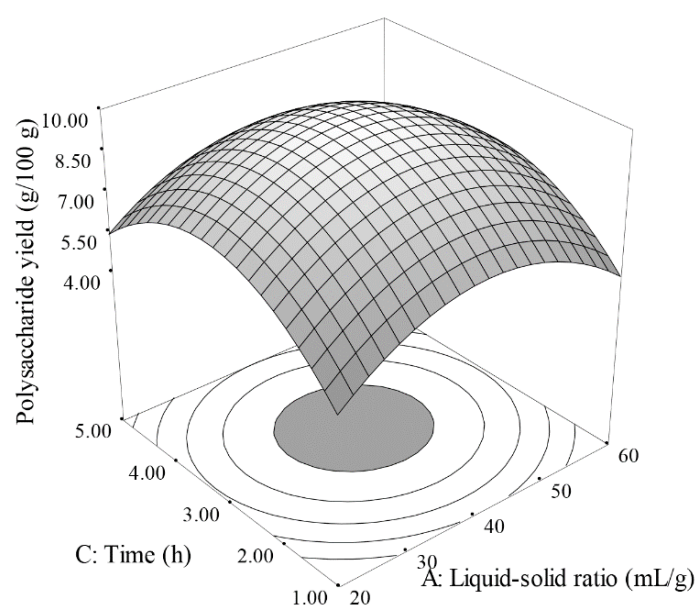

Figure 3. Response surface plot showing the effect of liquid-solid ratio and time on polysaccharides extraction from $A$. auricula fruit bodies. The temperature was constant at $80{ }^{\circ} \mathrm{C}$. 
resulted in decrease of red complexes. $\mathrm{Fe}^{2+}$-chelating activity of antioxidant could be estimated by measuring absorbance of reaction solution at $562 \mathrm{~nm}$.

The chelating activities of AAFB polysaccharides and BHT on $\mathrm{Fe}^{2+}$ are shown in Figure 4. AAFB polysaccharides possessed higher $(p<0.05) \mathrm{Fe}^{2+}$-chelating activity than BHT in a concentration-dependent manner. $\mathrm{IC}_{50}$ value $(0.43 \mathrm{mg} / \mathrm{mL})$ of AAFB polysaccharides with $\mathrm{Fe}^{2+}$-chelating activity was significant lower $(p<0.05)$ than BHT $(0.79 \mathrm{mg} / \mathrm{mL})$. At an identical concentration, chelating activity of AAFB polysaccharides on $\mathrm{Fe}^{2+}$ was stronger compared to that of polysaccharides from four mushroom Agaricus bisporus, Agaricus brasiliensis, Ganoderma lucidum and Phellinus linteus fruit bodies (Kozarski et al., 2011).

\subsection{Hydroxyl radical scavenging activity of AAFB polysaccharides}

Among all reactive oxygen radicals, hydroxyl radical was known as the most powerful radical. It could induce severe damage to adjacent biomolecules in the body, which result in cell damage that caused ageing, cancer and several other diseases (Yang et al., 2014). The removal of hydroxyl radical was probably one of the most effective ways to defense oxidative damage of

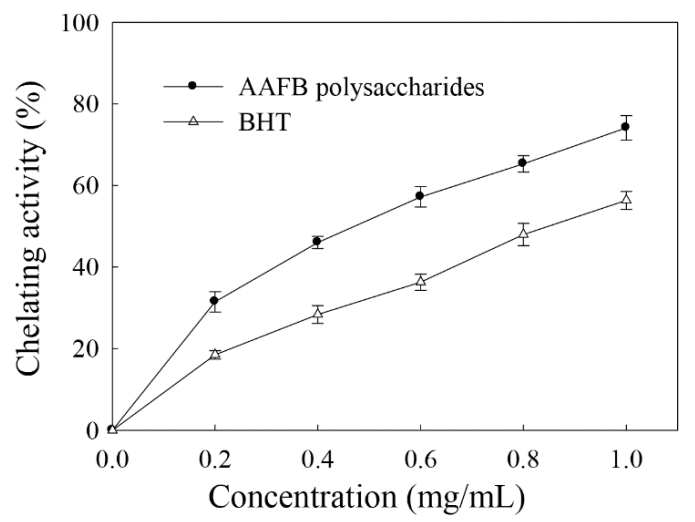

Figure 4. Chelating activity of AAFB polysaccharides on $\mathrm{Fe}^{2+}$. Values are means \pm SD of three independent determinations.

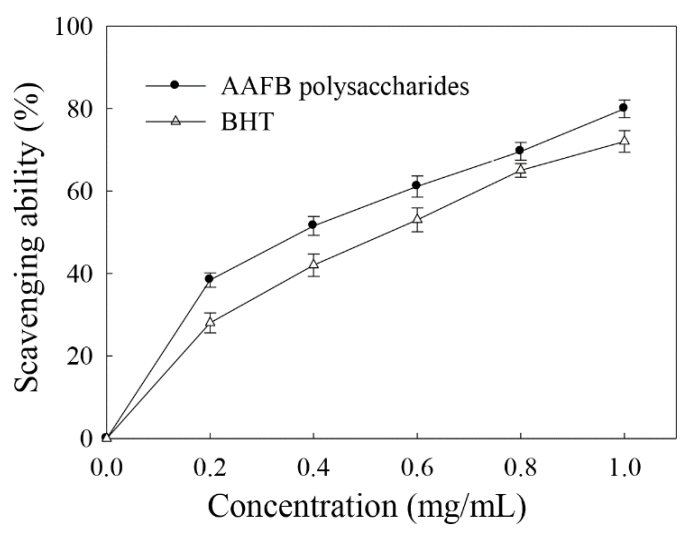

Figure 5. Scavenging activity of AAFB polysaccharides on hydroxyl radical. Values are means \pm SD of three independent determinations. human body. Therefore, hydroxyl radical scavenging activity was considered to be one of the most important antioxidant mechanisms.

The scavenging abilities of AAFB polysaccharides and BHT on hydroxyl radical are shown in Figure 5. With the increase of concentration, the scavenging abilities of AAFB polysaccharides and BHT on hydroxyl radical also increased. At the concentration range of $0.2-1.0 \mathrm{mg} / \mathrm{mL}$, AAFB polysaccharides showed significantly stronger $(p<0.05)$ scavenging activities than BHT. Meanwhile, $\mathrm{IC}_{50}$ value of AAFB polysaccharides was $0.38 \mathrm{mg} / \mathrm{mL}$, which was significant lower $(p<0.05)$ than BHT $(0.56 \mathrm{mg} / \mathrm{mL})$. At an identical concentration, scavenging activity of AAFB polysaccharides on hydroxyl radical was slightly stronger than that of polysaccharides from Gloeostereum incarnatum fruit bodies (Zhang et al., 2015). These results suggested that AAFB polysaccharides were better natural antioxidant than BHT in scavenging hydroxyl radical.

\section{Conclusions}

The extraction conditions of AAFB antioxidant polysaccharides were optimized by a three variable, three level Box-Behnken experiment design. Correlation analysis of the quadratic polynomial regression model indicated that the model could be employed to optimize conditions for polysaccharides extraction. The combination of liquid-solid ratio $(38.77 \mathrm{~mL} / \mathrm{g})$, temperature $\left(93.98^{\circ} \mathrm{C}\right)$ and time $(3.41 \mathrm{~h})$ was determined to obtain the highest polysaccharide yield $(10.46 \mathrm{~g} / 100 \mathrm{~g})$. The antioxidant activities of AAFB polysaccharides were evaluated by $\mathrm{Fe}^{2+}$-chelating ability and hydroxyl radical scavenging assay. It exhibited stronger antioxidant activity compared to BHT. Results from this study indicated that AAFB polysaccharides could be potentially used as a natural antioxidant.

\section{Acknowledgements}

This work was supported by the Doctor Research Fund of Dalian Nationalities University (No. 0701-110015).

\section{References}

Asatiani, M. D., Kachlishvili, E. T., Khardziani, T. S., Metreveli, E. M., Mikiashvili, N. A., Songulashvili, G. G., Tsiklauri, N. D., Wasser, S. P., \& Elisashvili, V. I. (2008). Basidiomycetes as a source of antioxidants, lectins, polysaccharides, and enzymes. Journal of Biotechnology, 136S, S717-S742. http://dx.doi.org/10.1016/j.jbiotec.2008.07.1706.

Chen, H., Ju, Y., Li, J., \& Yu, M. (2012). Antioxidant activities of polysaccharides from Lentinus edodes and their significance for disease prevention. International Journal of Biological Macromolecules, 50(1), 214-218. http://dx.doi.org/10.1016/j.ijbiomac.2011.10.027. PMid:22085754.

Chen, R., Jin, C., Li, H., Liu, Z., Lu, Z., Li, S., \& Yang, S. (2014). Ultrahigh pressure extraction of polysaccharides from Cordyceps militaris and evaluation of antioxidant activity. Separation and Purification Technology, 134(25), 90-99. http://dx.doi.org/ 10.1016/j. seppur.2014.07.017.

Derringer, G., \& Suich, R. (1980). Simultaneous optimization of several response variables. Journal of Quality Technology, 12(4), 214-219. 
Dinis, T. C. P., Maderia, V. M. C., \& Almeida, L. M. (1994). Action of phenolic derivatives (acetaminophen, salicylate, and 5-aminosalicylate) as inhibitors of membrane lipid peroxidation and as peroxyl radical scavengers. Archives of Biochemistry and Biophysics, 315(1), 161-169. http://dx.doi.org/10.1006/abbi.1994.1485. PMid:7979394.

Gungor, N., \& Sengul, M. (2008). Antioxidant activity, total phenolic content and selected physicochemical properties of white mulberry (Morus Alba L.) fruits. International Journal of Food Properties, 11(1), 44-52. http://dx.doi.org/ 10.1080/10942910701558652.

Kozarski, M., Klaus, A., Niksic, M., Jakovljevic, D., Helsper, J. P. F. G., \& Van Griensven, L. J. L. D. (2011). Antioxidative and immunomodulating activities of polysaccharide extracts of the medicinal mushrooms Agaricus bisporus, Agaricus brasiliensis, Ganoderma lucidum and Phellinus linteus. Food Chemistry, 129(4), 1167-1675. http://dx.doi. org/10.1016/j.foodchem.

Lianfu, Z., \& Zelong, L. (2008). Optimization and comparison of ultrasound/microwave assisted extraction (UMAE) and ultrasonic assisted extraction (UAE) of lycopene from tomatoes. Ultrasonics Sonochemistry, 15(5), 731-737. http://dx.doi.org/10.1016/j. ultsonch.2007.12.001. PMid:18226944.

Moskovitz, J., Yim, M. B., \& Chock, P. B. (2002). Free radicals and disease. Archives of Biochemistry and Biophysics, 397(2), 354-359. http://dx.doi.org/10.1006/abbi.2001.2692. PMid:11795894.

Rodrigues, S., Pinto, G. A. S., \& Fernandes, F. A. N. (2008). Optimization of ultrasound extraction of phenolic compounds from coconut (Cocos nucifera) shell powder by response surface methodology. Ultrasonics Sonochemistry, 15(1), 95-100. http://dx.doi.org/10.1016/j. ultsonch.2007.01.006. PMid:17400017.

Sevag, M. G., Lackman, D. B., \& Smolens, J. (1938). The isolation of the components of streptococcal nucleoproteins in serologically active form. The Journal of Biological Chemistry, 124(2), 425-436.

Sun, Y. X., \& Kennedy, J. F. (2010). Antioxidant activities of different polysaccharide conjugates (CRPs) isolated from the fruiting bodies of Chroogomphis rutilus (Schaeff.: Fr.) O. K. Miller. Carbohydrate Polymers, 82(2), 510-514. http://dx.doi.org/10.1016/j.carbpol.2010.05.010.

Tu, Y., Sun, Y., Tian, Y., Xie, M., \& Chen, J. (2009). Physicochemical characterisation and antioxidant activity of melanin from the muscles of Taihe Black-bone silky fowl (Gallus gallus domesticus Brisson). Food Chemistry, 114(4), 1345-1350. http://dx.doi.org/10.1016/j. foodchem.2008.11.015.
Wasser, S. P., \& Weis, A. L. (1999). Medicinal properties of substances occurring in higher basidiomycetes mushroom: Current perspective. International Journal of Medicinal Mushrooms, 1(1), 31-51. http:// dx.doi.org/10.1615/IntJMedMushrooms.v1.i1.30.

Xie, C., Gu, Z., You, X., Liu, G., Tan, Y., \& Zhang, H. (2010). Screening of edible mushrooms for release of ferulic acid from wheat bran by fermentation. Enzyme and Microbial Technology, 46(2), 125-128. http://dx.doi.org/10.1016/j.enzmictec.2009.10.005.

Yan, F., Yang, X., Liu, C., Huang, S., Liao, L., \& Fu, C. (2014). Extraction optimization of antioxidant polysaccharides from leaves of Gynura bicolor (Roxb. \& Willd.) DC. Food Science and Technology (Campinas.), 34(2), 402-407. http://dx.doi.org/10.1590/fst.2014.0055.

Yang, X., Yan, F., Huang, S., \& Fu, C. (2014). Antioxidant activities of fractions from longan pericarps. Food Science and Technology, 34(2), 341-345. http://dx.doi.org/10.1590/S0101-20612014005000034.

Zhang, A., Li, X., Xing, C., Yang, J., \& Sun, P. (2014). Antioxidant activity of polysaccharide extracted from Pleurotus eryngii using response surface methodology. International Journal of Biological Macromolecules, 65, 28-32. http://dx.doi.org/10.1016/j. ijbiomac.2014.01.013. PMid:24418337.

Zhang, M., Cui, S. W., Cheung, P. C. K., \& Wang, Q. (2007). Antitumor polysaccharides from mushrooms: a review on their isolation process, structural characteristics and antitumor activity. Trends in Food Science \& Technology, 18(1), 4-19. http://dx.doi.org/10.1016/j. tifs.2006.07.013.

Zhang, Z. F., Lv, G. Y., Jiang, X., Cheng, J. H., \& Fan, L. F. (2015). Extraction optimization and biological properties of a polysaccharide isolated from Gleoestereum incarnatum. Carbohydrate Polymers, 117, 185-191. http://dx.doi.org/10.1016/j.carbpol.2014.09.059. PMid:25498624.

Zou, Y., Xie, C., Fan, G., Gu, Z., \& Han, Y. (2010). Optimization of ultrasound-assisted extraction of melanin from Auricularia auricula fruit bodies. Innovative Food Science \& Emerging Technologies, 11(4), 611-615. http://dx.doi.org/10.1016/j.ifset.2010.07.002.

Zou, Y., Yang, Y., Zeng, B., Gu, Z., \& Han, Y. (2013). Comparison of physicochemical properties and antioxidant activities of melanins from fruit-bodies and fermentation broths of Auricularia auricula. International Journal of Food Properties, 16(4), 803-813. http://dx.doi. org/10.1080/10942912.2011.567433. 